\title{
A Dissatisfied Generation? An Age-Period-Cohort Analysis of the Political Satisfaction of Youth in Hong Kong from 1997 to 2014
}

\author{
Kevin Tze-wai Wong ${ }^{1} \cdot$ Victor Zheng $^{1} \cdot$ Po-san Wan ${ }^{1}$
}

Accepted: 7 November 2015/Published online: 13 November 2015

(C) Springer Science+Business Media Dordrecht 2015

\begin{abstract}
For this study, a comprehensive test was conducted on the net effects of age and cohort on political satisfaction in Hong Kong. We use a newly developed methodology of Age-Period-Cohort analysis known as the Cross-Classified Random Effects Model and a pooled dataset of repeated cross-sectional surveys from 1997 to 2014. The findings reveal a U-shaped relationship between age and political satisfaction, in which the level of satisfaction of the youth is between that of the middle-aged and elderly, while the middleaged express the least satisfaction and the elderly have the highest level of satisfaction. However, cohort effects are relatively weak. There is no evidence that later cohorts are less satisfied than earlier cohorts. These results indicate that the new generation is more politically dissatisfied due to their age rather than their cohort. We also find that period effects interact with age and cohort effects. The recent decline in the political satisfaction of 20-year-olds and of the cohort born in 1986 or later is more pronounced than that of older people and earlier birth cohorts. Under the rule of the current Chief Executive, young people were found to be much more dissatisfied than older people. The rise in the price of housing in recent years has also sharpened the differences in political satisfaction between those of different ages and cohorts.
\end{abstract}

Keywords Age-Period-Cohort analysis · Youth · Political satisfaction · Hong Kong

Kevin Tze-wai Wong

kevinwtw@cuhk.edu.hk

Victor Zheng

vzheng@cuhk.edu.hk

Po-san Wan

shirleywan@cuhk.edu.hk

1 Hong Kong Institute of Asia-Pacific Studies, The Chinese University of Hong Kong, Shatin, Hong Kong 


\section{Introduction}

Hong Kong, where more than $97 \%$ of the residents are Chinese, is a highly developed international city. Since its return to Chinese sovereignty in 1997, Hong Kong society has undergone dramatic changes. In recent years, Hong Kong's young people have become increasingly dissatisfied with the government and more active in social movements. On 22 September 2014, thousands of students started a week-long boycott of classes, demanding the overturn of the strict rules set by the Standing Committee of the National People's Congress on candidate nominations for the 2017 Chief Executive election. This boycott later turned into a large-scale social movement, the so-called Occupy Central Movement or Umbrella Movement. Thousands of protestors occupied the main roads outside the government headquarters complex and paralyzed public transportation in other key areas of the city. The movement lasted for 79 days before the police took action in December to clear the areas occupied by protestors. The eruption of this large-scale social movement demonstrates the high level of political dissatisfaction felt by the young people. A growing number of studies have been conducted to explain why young people have become more dissatisfied in recent years.

However, existing studies on political satisfaction in Hong Kong are mostly concerned with age group differences at a given time point without a simultaneous assessment of the age, time period, and birth cohort effects. This is because such studies are invariably based on a single dataset of a cross-sectional survey, and suffer from an identification problem induced by the exact linear dependency between age and cohort (Cohort $=$ Period - Age). This creates two research limitations that prevent us from understanding the political satisfaction of young people (Yang 2008). First, assessing the net effect of age and cohort is disallowed. Confounding these two effects prevents us from ascertaining whether those in the young age groups are dissatisfied or whether later cohorts are dissatisfied, or if both are dissatisfied. Second, little attention has been paid to the possibility of heterogeneity in the period effect over the course of life and across successive birth cohorts. The effects of various external environments on political satisfaction may shift over the course of life and across successive cohorts.

It is imperative to distinguish between the net effects of age and cohort, in that they carry different explanatory mechanisms for the young people's low level of political satisfaction. There are two common explanations for the rise in the political dissatisfaction of young people in Hong Kong. One explanation from the cohort perspective suggests that the young generation enjoyed a higher-quality environment when growing up than previous generations did, and have therefore been socialized with post-materialistic values such as autonomy, freedom, and self-expression, and have higher political aspirations than those of previous generations. Because of this difference in mentality and value orientation from their seniors, young people show a greater tendency to take on the role of "vanguards" in social movements. Another explanation grounded in the age group perspective stresses the materialistic needs and problems of the young. For the past decade, Hong Kong has been facing serious challenges such as rising housing prices and dwindling chances for promotion, frustrating young people who hope to start their own families and develop their own careers.

Our study aims to examine the net effects of age and cohort on political satisfaction in Hong Kong and explore possible heterogeneities in the period effect among various age groups and birth cohorts, by using a pooled dataset of repeated cross-sectional surveys from 1997 to 2014 and a newly developed methodology of Age-Period-Cohort (APC) 
analysis known as the Cross-Classified Random Effects Model (CCREM). First, a brief review of relevant theories of age, cohort, and period effects is presented. Then, the datasets, variables, and statistical method used in this study are introduced. Finally, we present our findings and conclude the paper with a discussion of the research implications.

\section{Theories of Age, Cohort, and Period Effects}

Age, cohort, and period carry three unique impacts, although all are time-related variables. The age effect refers to the variations associated with changes in the course of life that people go through in the same way when they age, with the accumulation of experience, role or status changes, as well as biological maturation and decline. The cohort effect refers to each new birth cohort's entry into adult life with distinctive values formed by early life experiences in the same years, such as their initial condition in life and education in childhood. These values affect a human being's attitudes and behaviours for the remainder of his or her life, producing systematic differences between generations. The period effect refers to shifts in the social, cultural, or physical environments that affect all age groups in a society simultaneously for a term of years (Glenn 2003; Robinson and Jackson 2001; Yang and Land 2008).

\subsection{Age Effects}

Existing studies on the net effect of age group mainly discuss its impact on life satisfaction. Based on the role theory of aging, Gove et al. (1989) suggested that people have a more positive sense of self in early adulthood and that this sense of self declines with age because the transition in role that occurs from youth to middle age leads to some troubles and creates more stress. However, the old people appear to be well adjusted, more at ease socially, and more positive so they have more positive attributes than middle-aged adults. Blanchflower and Oswald (2004) share the view that young people and old people are happier than middle-aged people. They believe that changes in subjective well-being through the life cycle is a process of adapting to circumstances and that people will relinquish some of their aspirations and thereby enjoy their life more after the middle period of their life.

In the past decade, many empirical studies have found a U-shaped relationship between age and subjective well-being, in which the level of life satisfaction tends to reach its minimum in middle age (Brockmann 2010; Li 2015). Using 14 waves of British panel data, Clark (2007) offered evidence of a U-shaped relationship between age and subjective wellbeing that is independent from the cohort effect. After controlling for different cohorts, Blanchflower and Oswald (2008) demonstrated the existence of a similar U-shape through the course of life of people not only in Great Britain, but also in the United States and other developed and developing countries in Eastern Europe, Latin America, and Asia. This curvilinear relationship is also found in Chinese society. In Tang's (2014) analysis of people in mainland China, a curvilinear and concave relationship between age and life satisfaction was found when controlling for the cohort effect. Middle-aged people expressed the least satisfaction, while elderly people had the highest level of satisfaction. The life satisfaction level of young people was between that of the middle-aged and the elderly. 
People's life satisfaction was found to have a positive impact on their attitude toward the government (e.g., Kotzian 2010; Lipset and Schneider 1983; Lu 2014; Wong et al. 2009). Therefore, we can hypothesize that age and political satisfaction are in a curvilinear relationship, in which middle-aged people are less satisfied than young people and the elderly, although empirical research on the net effect of age on political satisfaction is lacking.

Moreover, some scholars believe that young people hold different values from elderly people. The life-cycle characteristics of youth, such as a high level of energy, increased cognitive awareness, the search for independence, identity, and fidelity, as well as a focus on the relationship between self and society, make young people more liberal and critical (Braungart and Braungart 1986). When individuals grow older, they become more conservative and moderate. Hence, the political satisfaction level of young people should be lower than that of elderly people (Wang 2010). Based on the above studies, two hypotheses are put forward:

H1 Middle-aged people are less politically satisfied than young people and the elderly.

H2 Young people are less politically satisfied than the elderly.

\subsection{Cohort Effects}

According to Mannheim (1952), a cohort is formed not only on the basis of a shared birth year but also on that of a common location in the historical dimension of social process. Braungart and Braungart (1986) pointed out that a cohort is a group of persons born around the same time who share the same set of particularly meaningful social and historical events at the youth stage of the development of the life cycle. Dramatic social and historical events, such as an economic depression, war immigration, and cultural change, have a particularly strong impact on the political attitudes of young people, who are in their formative stage of political learning. The political attitudes formed during a cohort's youth do not change appreciably over the life cycle. Jewell and Kambhampati (2015) find a link between youth happiness levels and adult life satisfaction that is independent from demographic and socioeconomic conditions.

As mentioned before, most empirical studies fail to examine the net effect of birth cohort on political satisfaction due to the problem of identification. Nevertheless, several scholars have proposed different possible directions for the effect of cohort on political satisfaction. The theme of post-materialism suggests that later cohorts are less satisfied with the government than earlier cohorts, because the higher quality of the living environment in their childhood inclines the later cohorts toward post-materialistic values such as autonomy and self-expression, encouraging them to be critical citizens. A critical citizen tends to evaluate the political authorities based on more demanding standards than would be held by an uncritical citizen, and to be less deferential to authority. This reduces the later cohort's support for the government and other hierarchical institutions (Inglehart 1977, 1999; Quaranta 2015). Since the Hong Kong youth displayed a strong tendency to take on the role of "vanguards" of post-materialistic values by actively participating in the 2015 Occupy Central Movement, some local commenters believed that Hong Kong latest cohort has higher political aspirations and is more critical of the government than earlier cohorts. Thus, they would be more likely to be politically dissatisfied.

In contrast, some scholars have put forward the opposite view-that the political satisfaction level of earlier cohorts is lower than that of successive cohorts. Ryder's (1965) 
classic cohort analysis emphasizes that individuals are particularly impressionable early in the course of their life. Elder (1974) stated that difficult experiences in childhood and young adulthood, such as economic depression and wars, may lead to a lower level of satisfaction. In Hong Kong, the cohorts born before the 1950s had experienced the Second World War and the Chinese Civil War. Hong Kong in the early post-war period was a less developed place than it became after its establishment as a financial centre in East Asia in the late 1980s. Most of the earlier cohorts migrated from mainland China, where living standards were lower than in Hong Kong. Moreover, in the 1970s or earlier the Hong Kong government was more corrupt and less effective than it became in the 1980s and onwards. The negative image of the government held by the earlier cohorts was formed in their childhood and young adulthood, and would not necessarily change significantly over their life. Given their difficult experiences in childhood and young adulthood, earlier cohorts may exhibit a lower level of political satisfaction than later cohorts. Hence, there is no consensus on the direction of the effect of cohort on political satisfaction. Two theories of the cohort effects on political satisfaction may be applicable to Hong Kong. We put forward the following hypothesis:

H3 Political satisfaction varies with birth cohorts.

\subsection{Period Effects}

Overall, the public's evaluation of the Hong Kong Special Administrative Region (HKSAR) government has decreased over the last several years. According to the Hong Kong Institute of Asia-Pacific Studies' (2015) longitudinal telephone survey research project, the proportion of the public expressing dissatisfaction with the government's performance increased from $31.7 \%$ in July 2012 to $44.6 \%$ in December 2014. Public distrust of the government increased from 28.4 to $37.8 \%$. One possible reason for the rise of public dissatisfaction in recent years is the election of Chun-ying Leung as Hong Kong's Chief Executive in 2012. Leung is widely suspected to be an underground member of the Chinese Communist Party and to hold very conservative political views, while the former Chief Executive Donald Tsang was a former senior civil servant and official since the colonial period. Hong Kong people fear that Leung would suppress the opposition and bring more intervention from the Central Government in local politics (Ma 2015). In addition, since the 2012 Chief Executive election, Leung has been involved in a number of scandals, such as concealing payments from the engineering firm UGL and building an illegal structure in his home.

More particularly, Leung has failed to prevent the price of housing from soaring, even as increasing home ownership was his key election promise. Housing is a very important topic in Hong Kong politics, especially in recent years. Our longitudinal survey project conducted by the Hong Kong Institute of Asia-Pacific Studies found that an increasing proportion of respondents, from $5.2 \%$ in 2009 to $28.2 \%$ in 2014, selected housing as the policy area about which they were most concerned. Housing has become their highestpriority policy area, and one that the respondents would like to see the Hong Kong government deal with first. Nowadays, in Hong Kong, young people prefer to move out of the family home and live alone, so many of them apply for public housing when they are still university students. Young people are expressing higher expectations of this policy area. In 2014, the proportion of those aged 30 or below who selected housing as the highest-priority policy area was $44.6 \%$, higher than the percentage for the general public. The failure to stop housing prices from continuously rising has driven up the Hong Kong 
people's level of dissatisfaction with the government, especially the young people (Cheng 2014).

It is important to note that the trend in satisfaction can be different for different age groups (Yang 2008). A change in role over the course of life can be attributed to differential exposures to the same periodic events. Different age groups hold different attitudes toward the same policy, politicians, political parties, as well as other social and political events. Also, period effects are believed to interact with cohort effects in the life of an adult (Braungart and Braungart 1986). Since values and demands vary across birth cohorts, a government policy may satisfy particular cohorts, but sacrifice the interests of other cohorts. Hence, there may be variations in the trend of the political satisfaction level among age groups and birth cohorts in Hong Kong. As there has been a rise in youth movements in recent years, such as the Against Moral and National Education Movement in 2012, we hypothesize that:

H4 The decline in the political satisfaction level of young people in recent years is greater than that of older people.

H5 The decline in the political satisfaction level of the latest cohorts in recent years is greater than that of earlier cohorts.

As mentioned before, Leung's rule and the rise in housing prices are believed to have led to the rise of the youth movement. Therefore, the following hypotheses are put forward:

H6 The negative impact of Leung's rule on the political satisfaction of young people is greater than that on older people.

H7 The negative impact of Leung's rule on the political satisfaction of the latest cohorts is greater than that on earlier cohorts.

H8 The negative impact of the rise in the price of housing on the political satisfaction of young people is greater than that on older people.

H9 The negative impact of the rise in the price of housing on the political satisfaction of the latest cohorts is greater than that on earlier cohorts.

\section{Data, Variables, and Methodology}

\subsection{Sample}

In order to generalize about life cycle experiences and birth cohort variations, it is necessary to have a longitudinal dataset that includes the information for the given cohorts as they age (Easterlin 2006). Hence, we use data from a longitudinal telephone survey research project that has been conducted monthly since July 1997. Two steps are involved in obtaining the samples for this survey project. First, a fixed set of telephone numbers is randomly selected from the latest Hong Kong Residential Telephone Directory. To cover unlisted and new numbers, the last two digits of the selected telephone numbers are replaced with two randomly selected digits within the range of 00-99. Second, after successfully reaching the selected residence, a family member aged 18 or above is selected for an interview in accordance with the last birthday rule. For every valid telephone 
number, a maximum of three contacts at different times is made before the number is classified as "unanswered".

By December 2014, 209 surveys had been completed. More than 160,000 respondents were successfully interviewed. After a listwise deleting of cases with missing values on the dependent and independent variables, the pooled dataset consisting of these 209 surveys contained an average of about 740 observations for each survey. The response rate for each survey was around $47 \%$. The aim in this survey project is to chart changes in public attitudes toward the HKSAR after the 1997 handover. Therefore, the demographic characteristics and political satisfaction of Hong Kong people have been repeatedly measured since 1997. This dataset is thus very suitable for use in the APC analysis on political satisfaction in Hong Kong.

\subsection{Dependent, Independent, and Control Variables}

The aim in our study is to test the net effects of age and cohort on political satisfaction in Hong Kong. In all of the surveys, the respondents were asked a series of questions about their attitudes toward the HKSAR government. To measure political satisfaction, the respondents were asked how satisfied they were with the performance of the HKSAR government. The responses ranged from 1 to 3 , with $1=$ dissatisfied, $2=$ neither satisfied nor dissatisfied, and $3=$ satisfied. The respondents were also asked to rate the performance of the Chief Executive. The responses ranged from 0 to 100, with a higher score indicating a more positive rating. Both satisfaction with the government and the rating of the Chief Executive were selected as dependent variables. We conducted an APC analysis on the two indicators of political satisfaction, respectively.

Under the framework of the APC analysis, independent variables are classified into an individual-level and a group-level variable. The respondent's age is the key individuallevel independent variable. The respondents range in age from 18 to 97 . The square of the age is also included in the analysis, because we hypothesize that a curvilinear relationship exists between age and political satisfaction, in which middle-aged people are less satisfied than young people and the elderly. Following the practice of Yang and Land (2008), we simply selected gender $(0=$ male, $1=$ female $)$ and education $(0=$ secondary educated or below, $1=$ tertiary educated) as the individual-level control variables.

Cohort and period are group-level variables. The oldest cohort member was born in 1906 and the youngest was born in 1996. As the convention is to form five-year birth cohort groups (Yang and Land 2013), the respondents were classified into nine five-year birth cohort groups starting from those born before 1951 to those born in 1986 or later. There were an average of 17,000 observations for each cohort. The first cohort was the largest, with about 28,000 observations, and the last was the smallest, with about 10,000 observations. Regarding the periods, as 209 surveys had been conducted in different months of different years, the respondents were classified into 209 months of survey years, ranging from July 1997 to December 2014.

In order to further explain possible variations in period effects among age groups and birth cohorts, we put forward hypotheses on the impacts of a change in the Chief Executive and a rise in housing prices on political satisfaction. These two group-level variables are included in our analysis. Since the transfer of sovereignty in 1997, there have been three Chief Executives. They are Chee-hwa Tung from July 1997 to March 2005, Donald Tsang from March 2005 to June 2012, and Leung from July 2012 to the present. The rule of the Chief Executive is coded as two dummy variables, which are rule of Tung and Tsang according to the time of the survey. The period of Leung's rule is the reference group. The 
price of housing is measured in terms of the Centa-City Index (CCI), which is a monthly index based on all records of transactions registered with the Land Registry to reflect movements in the prices of secondary private residential properties (Centadata 2015). The summary statistics of all variables are presented in the "Appendix".

\subsection{Age-Period-Cohort Analysis}

A number of APC analysis models have been developed in recent decades to solve the problem of identification. Yang and Land (2006) developed a mixed models approach, known as the CCREM, for the APC analysis of micro datasets in the form of a series of repeated cross-sectional sample surveys. This model is superior to a conventional fixed effects regression with a series of dummies for the period and cohort effects estimated by ordinary least squares, in that fixed effects models do not take into account the effects of the contextual variables, so they tend to underestimate standard errors and overestimate $t$ tests. Fixed effects models also do not allow for the possibility of unexplained variances across cohorts and periods, which is not an appropriate assumption in an APC analysis (Yang and Land 2008).

The CCREM is a mixed model consisting of individual-level (Level 1) and group-level (Level 2) models, which estimate the fixed effects of age and other covariates and the random effects of period and cohort. A Level 1 model can be specified as follows:

$$
\mathrm{Y}_{\mathrm{ijk}}=\alpha_{\mathrm{jk}}+\sum_{n=1} \beta_{\mathrm{njk}} \mathrm{X}_{\mathrm{nijk}}+e_{\mathrm{ijk}}
$$

where $Y_{i j k}$ is the dependent variable for an individual $i$ of birth cohort $j$ in period $k, \alpha_{j k}$ is the intercept parameter for the regression model, $\beta_{\text {njk }}$ denotes the effects of covariate $n$, $\mathrm{X}_{\mathrm{nijk}}$ is covariate $\mathrm{n}$, such as age, of an individual $\mathrm{i}$ of birth cohort $\mathrm{j}$ in period $\mathrm{k}$, and $e_{\mathrm{ijk}}$ is the normally-distributed random error term.

Level 2 models are for examining period and cohort effects through specifying random variance components for the random intercept and coefficient, and to test whether the effect of individual attributes varies by period or cohort. Hence, the intercept and coefficients in Eq. (1) is modelled as:

$$
\begin{aligned}
& \alpha_{\mathrm{jk}}=\pi_{0}+u_{0 \mathrm{j}}+v_{0 \mathrm{k}} \\
& \beta_{\mathrm{njk}}=\pi_{\mathrm{n}}+u_{\mathrm{nj}}+v_{\mathrm{nk}}
\end{aligned}
$$

where $\pi_{0}$ is the expected mean averaged over all cohorts and periods, $u_{0 \mathrm{j}}$ is the overall cohort effects in terms of residual random effects coefficients of cohort $\mathrm{j}$ averaged over all time periods, $v_{0 \mathrm{k}}$ is the overall period effects in terms of residual random effects coefficients of period $\mathrm{k}$ averaged over all birth cohorts, $\pi_{\mathrm{n}}$ represents the fixed effect of individual attribute $\mathrm{n}, u_{\mathrm{nj}}$ is the cohort effects on individual attribute n's coefficient in terms of residual random effects coefficients of cohort $\mathrm{j}$ averaged over all time periods, and $v_{\mathrm{nk}}$ is the period effects on individual attribute n's coefficient in terms of residual random effects coefficients of period $\mathrm{k}$ averaged over all birth cohorts (Yang 2008). Following the practice of Land and Yang (2008), the CCREM analyses in our study were made using restricted maximum likelihood (REML) estimation methods. 


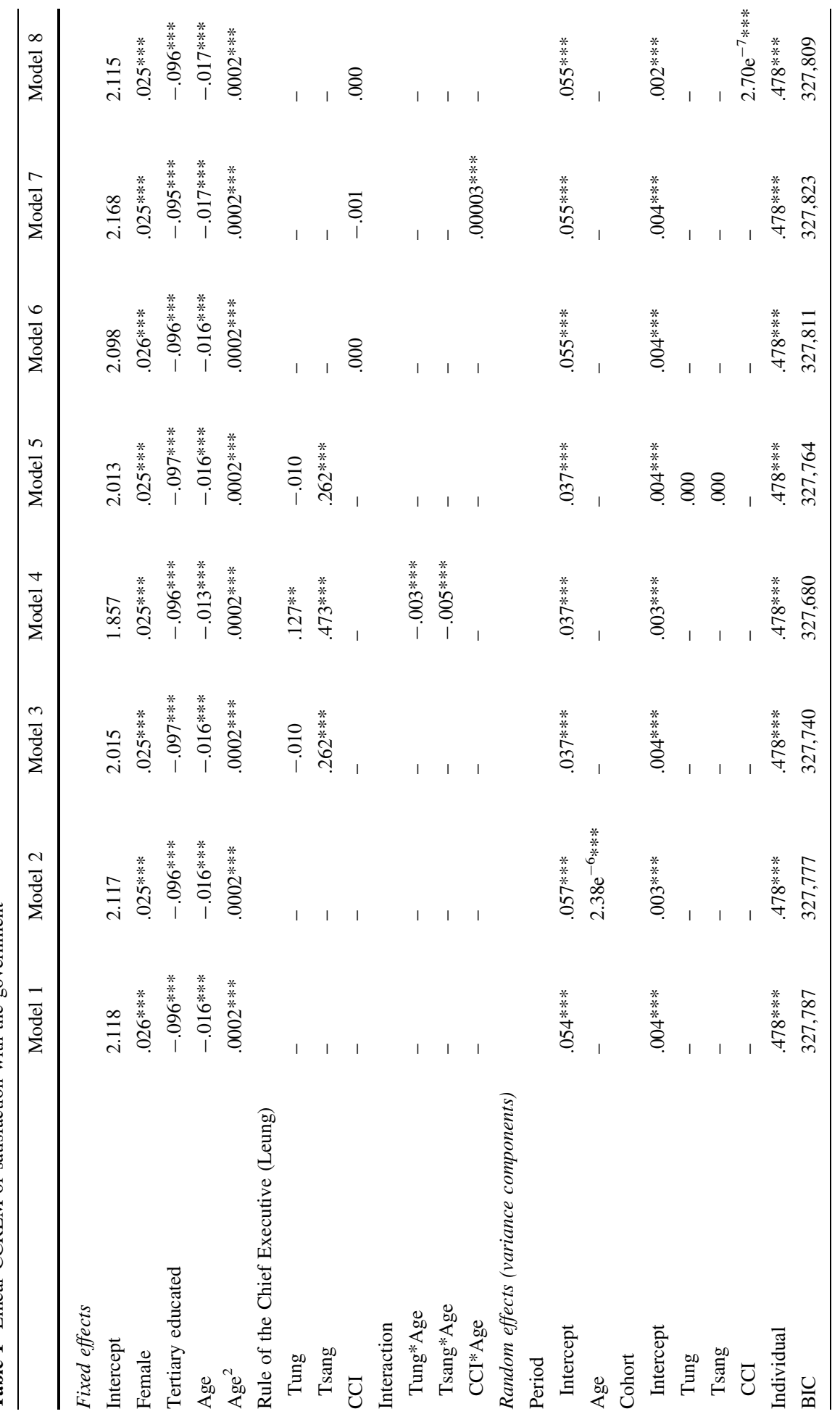




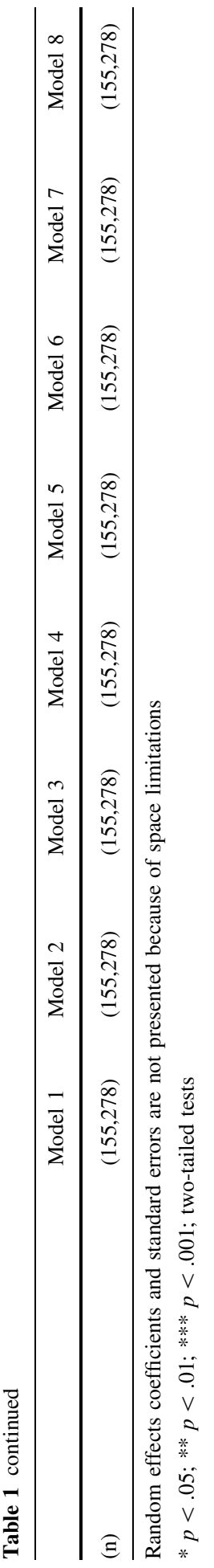

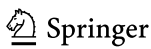




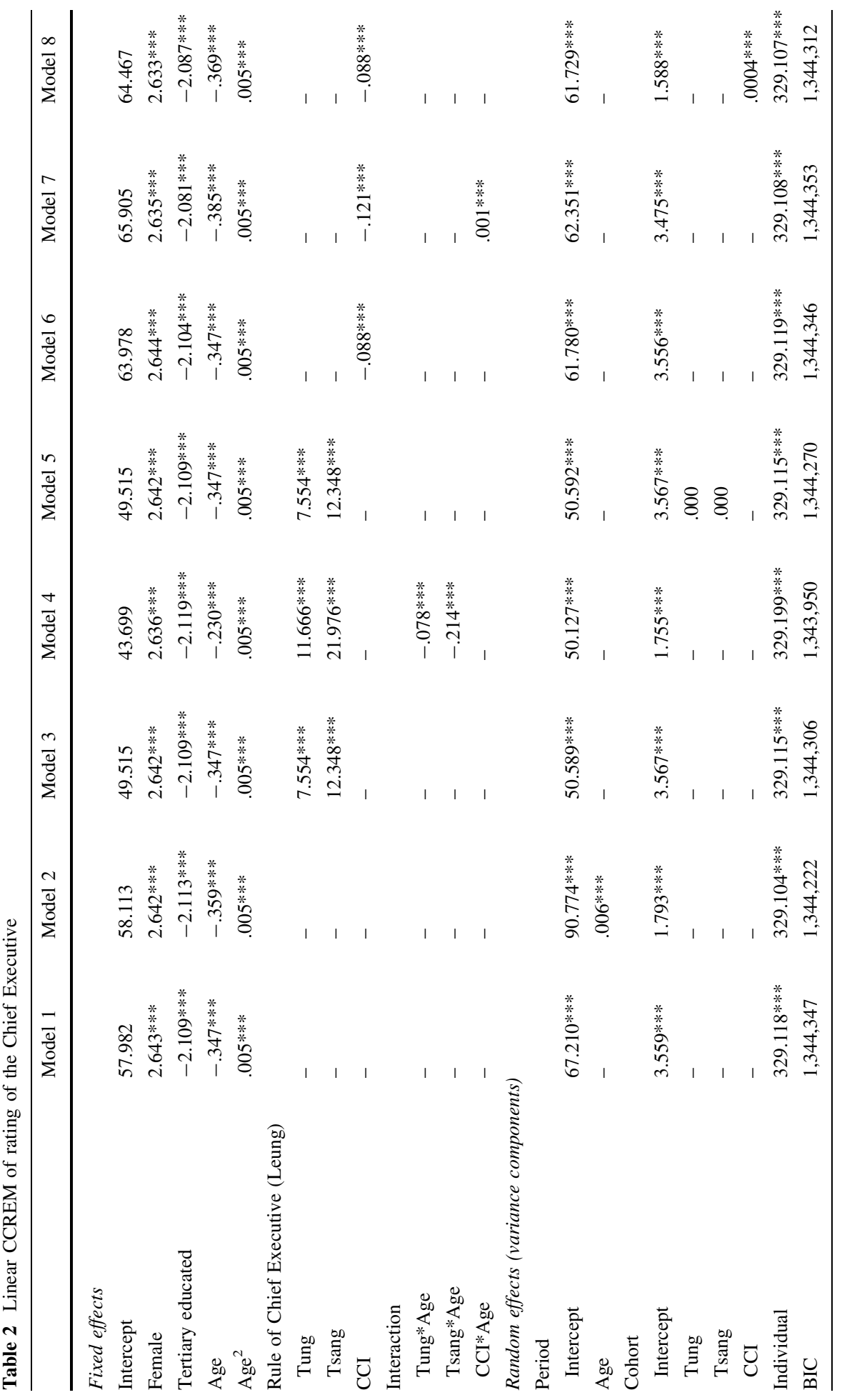




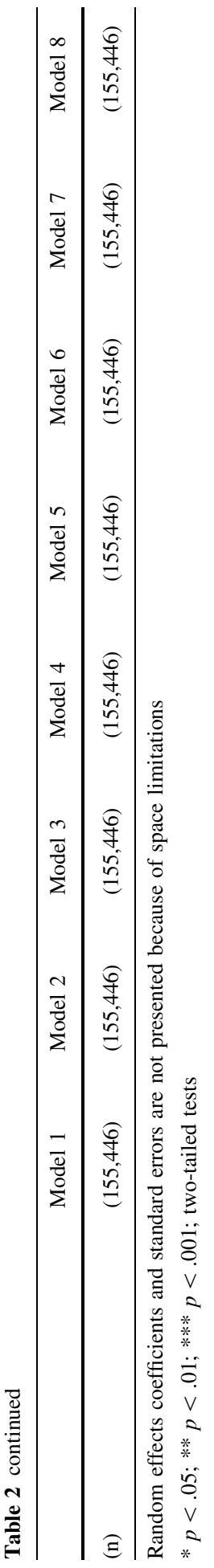

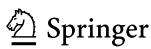




\section{Results and Findings}

Tables 1 and 2 present estimates of fixed effects coefficients and random effects variance components from CCREM analyses on satisfaction with the government and the rating of the Chief Executive. We first examine the net effects of age and cohorts on satisfaction with the government and the rating of the Chief Executive. Next, we investigate the possible differences in age groups and birth cohorts in the time trend of two indicators of political satisfaction. Finally, we test the hypotheses on differences in the impacts of Leung's rule and of housing prices across the course of life and across birth cohorts. Predicted levels of two dependent variables are displayed in graphs taken from selected models to illustrate the key findings.

\subsection{Overall Age and Cohort Effects}

Model 1 is the basic model of the APC analysis controlling for the effects of gender and education level. Figure 1 presents the predicted level of satisfaction with the government and the rating of the Chief Executive of various age groups and birth cohorts estimated from Model 1. In Tables 1 and 2, age and its square pass the significance level. The coefficients of the former are negative and that of the latter are positive. Figure 1a shows the estimated effects of age at the mean of the control variables and averaged over all cohorts and periods, demonstrating a curvilinear and concave relationship of age with satisfaction with the government and the rating of the Chief Executive. The political satisfaction level decreases with age at the early stage of the course of life. It bottoms out at around the age of 40 for satisfaction with the government and 35 for the rating of the Chief Executive. Later, it begins to rise and surpasses the level of 20-year-olds when individuals are around the age of 60 for satisfaction with the government and 50 for the rating of the
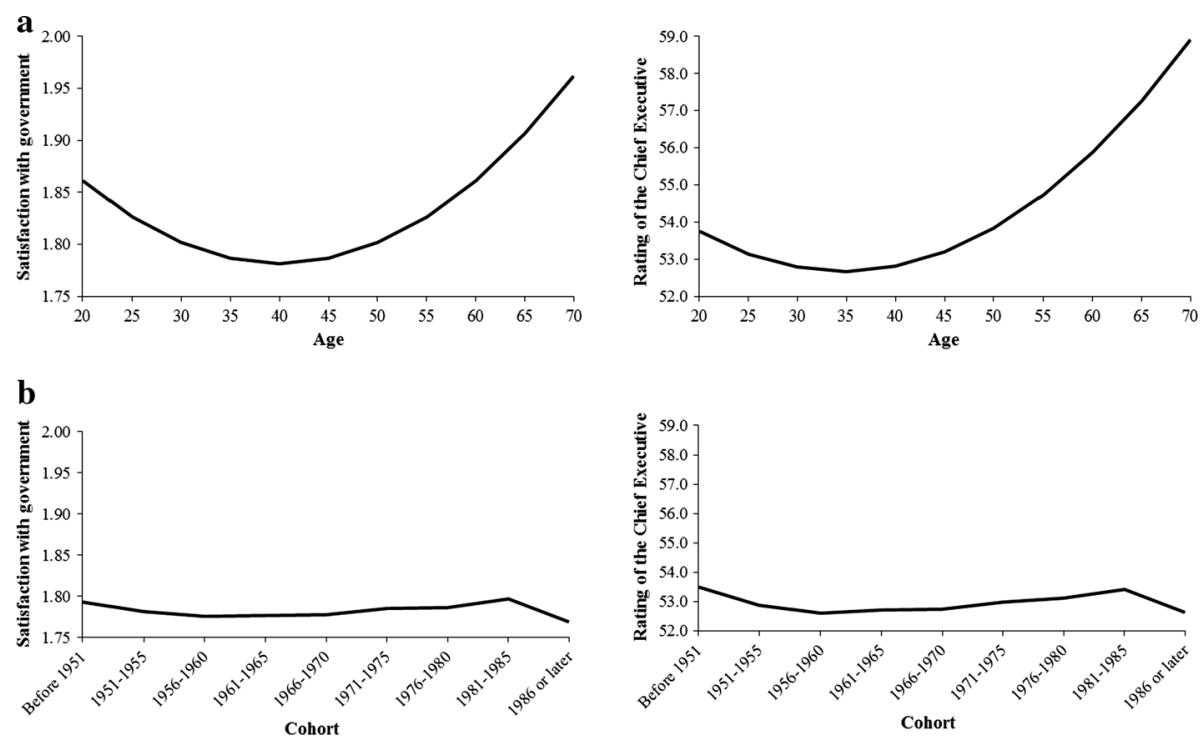

Fig. 1 Overall age and cohort effects on political satisfaction, a age effects, b cohort effects. Note The effects in terms of the predicted value of political satisfaction are estimated from Model 1 
Chief Executive. In general, the political satisfaction level of young people is between that of the middle-aged and the elderly, while middle-aged people are the most dissatisfied and the elderly are the most satisfied. These findings support our first two hypotheses.

The cohort variance components in Tables 1 and 2 are statistically significant, supporting our third hypothesis. Figure $1 \mathrm{~b}$ displays the estimated cohort effects in terms of the predicted level of satisfaction with the government and the rating of the Chief Executive at the mean of age and averaged over all periods. This is calculated as $\hat{\alpha}_{\mathrm{j}}=\hat{\pi}_{0}+u_{0 \mathrm{j}}$, where $\hat{\pi}_{0}$ is the estimated overall mean from model 1. It demonstrates a drop in the predicted level of satisfaction with the government and the rating of the Chief Executive from the cohort born between 1981 and 1985 to those born in 1986 or later. However, this is insufficient to conclude that the latest cohort is the most dissatisfied, because the individual birth cohort random effects coefficient of the cohort born in 1986 or later is statistically insignificant. Their predicted level of satisfaction with the government and rating of the Chief Executive
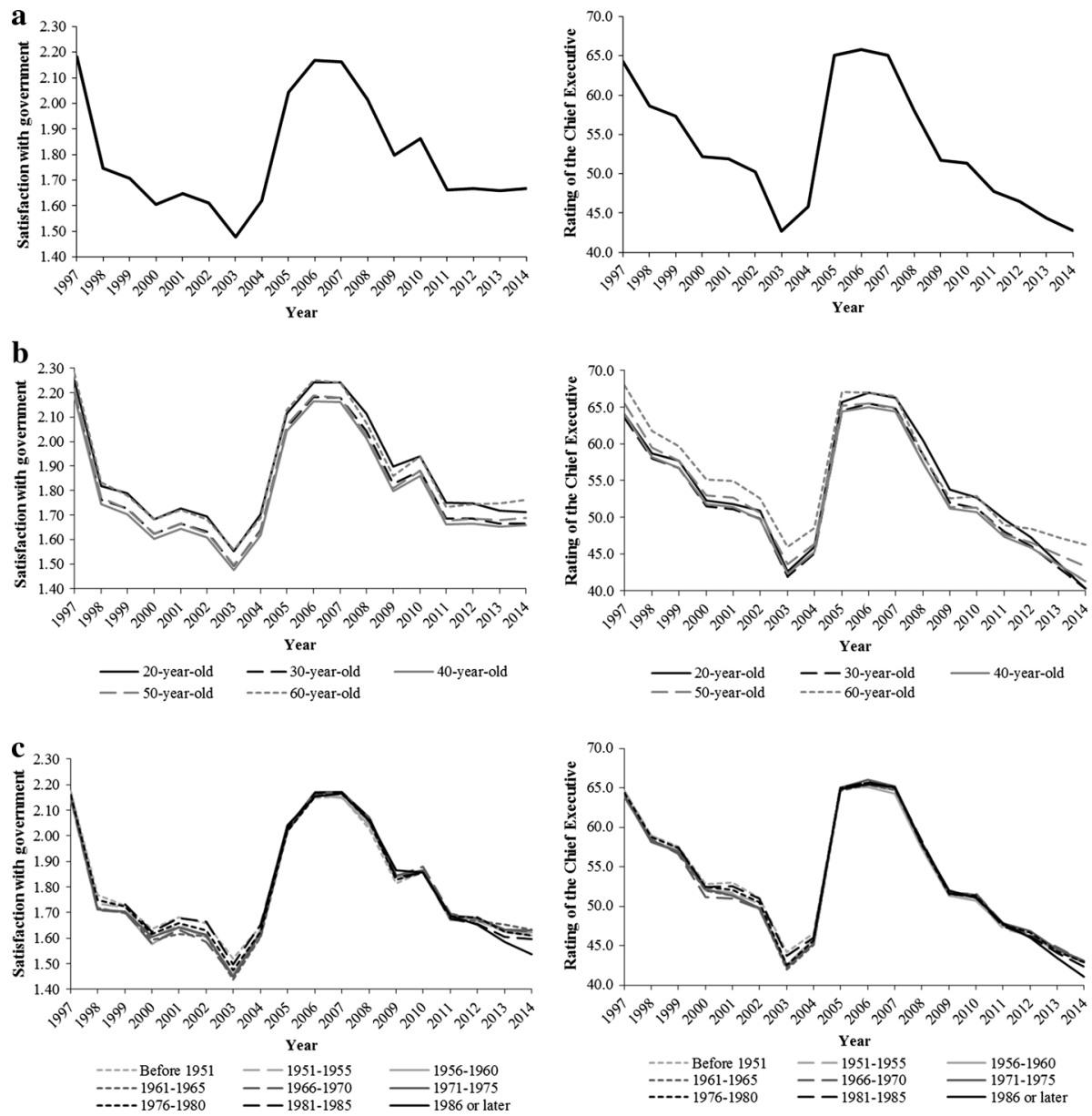

Fig. 2 Predicted period variations in political satisfaction by age and cohort, a Model 1: overall period effects, b Model 2: period effects by age, c Model 2: period effects by cohort. Note The effects in terms of the predicted value of political satisfaction are estimated from Models 1 and 2 
is similar to those of some earlier cohorts, including the cohort born between 1956 and 1960 and that between 1961 and 1965. On the other hand, the second-latest cohort-the cohort born between 1981 and 1985-is the most satisfied of all of the cohorts to as far back as the earliest cohort, those born before 1951. Moreover, the cohort effects are small relative to the age effects. The predicted level of satisfaction with the government varies from 1.769 to 1.797 and the rating of the Chief Executive varies from 52.618 to 53.506 across birth cohorts, which is smaller than age variation, which is from 1.782 to 1.962 for satisfaction with the government and from 52.675 to 58.905 for the rating of the Chief Executive. Therefore, the cohort trend is generally flat, indicating no linear increases or decreases.

The absence of a clear trend in political satisfaction across cohorts may be because the effects of early life experiences are mixed. Although a higher-quality growing environment has caused the later cohorts to become more inclined to espouse post-materialistic values, and thus to have higher political expectations of the government, the well-developed social situation helped to build a more positive image of the government during the childhood and young adulthood of the later cohorts. In contrast, the standard of living in childhood and young adulthood of the earlier cohorts was lower. The Hong Kong government in this period was also more ineffective and corrupt. Their difficult experiences in childhood and young adulthood caused the earlier cohorts to hold a more negative attitude towards the government. However, due to these experiences the earlier cohorts may downplay their non-materialistic needs and be more tolerant of minor mistakes committed by the current government.

Our findings in Model 1 show that age effects have a stronger impact on political satisfaction than the cohort effect. There are two important implications to this. One is that current life experience has a stronger explanatory power for the political satisfaction of Hong Kong people than early life experiences. Another is that in Hong Kong young people are more politically dissatisfied due to their age rather than their cohort. Differences in childhood and early adulthood experiences between the latest cohort and earlier cohorts are insufficient to explain why young people in Hong Kong are more dissatisfied than elderly people.

\subsection{Trend by Age and Cohort}

Figure 2 shows the period effects in terms of the predicted level of satisfaction with the government and the rating of the Chief Executive, and indicates different time patterns for various age groups and birth cohorts. In Model 1, the period variance components in Tables 1 and 2 are statistically significant. Figure 2a displays the estimated overall period effects in terms of the predicted level of satisfaction with the government and the rating of the Chief Executive at the mean of age and averaged over all cohorts, which is calculated as $\hat{\alpha}_{\mathrm{k}}=\hat{\pi}_{0}+v_{0 \mathrm{k}}$. ${ }^{1}$ The trend in the level of satisfaction with the government is similar with that of the rating of the Chief Executive. The period effects show a downward trend in political satisfaction in the first few years after the handover in 1997. Hong Kong suffered from an economic recession for several years after the 1997 Asian Financial Crisis. Political satisfaction bottomed out in 2003, when the severe acute respiratory syndrome

\footnotetext{
1 In original estimation, the period coefficients are calculated for each month. For convenience, in the figure of period effects, we select random effects coefficients for each year instead, which can be computed by averaging month-specific random effects coefficients for each year, weighted by sample sizes for each month, similarly hereinafter.
} 
(SARS) erupted, leading to serious social panic. All of this, in addition to the proposal to bring into law a controversial national security bill in accordance with Article 23 of the Basic Law, prompted 500,000 people to participate in the July 1st Protest that year, to express their dissatisfaction with the government. In order to rebuild public confidence, the Hong Kong government actively signed a policy agreement with the Central Government on economic integration between the mainland and Hong Kong. This policy agreement is called the Mainland and Hong Kong Closer Economic Partnership Arrangement (CEPA). Afterwards, the level of political satisfaction in Hong Kong began to rise. After the experienced official Tsang replaced Tung as the Chief Executive in 2005, the public's political satisfaction rose to its highest level—matching that in 1997. However, it fell again after 2007. The decline continued, even after Leung was elected as the third Chief Executive in 2012. In 2014, the rating of the Chief Executive was as low as that in 2003. Then, in September 2014, the Occupy Central Movement erupted.

To examine whether the decrease in the level of political satisfaction of younger people has become more pronounced in recent years, random period variations in the age coefficient are considered in Model 2. The period variance components for the age coefficient in Tables 1 and 2 are statistically significant, indicating different trends in the level of satisfaction with the government and the rating of the Chief Executive for various age groups. Figure $2 \mathrm{~b}$ presents the estimated overall period effects by age groups in terms of the predicted level of satisfaction with the government and the rating of the Chief Executive for each year at the mean of the control variables and averaged over all cohorts estimated from Model 2. With regard to the 20-year-old individuals, we first calculated their estimated level of satisfaction as $\hat{\pi}_{0}+v_{0 \mathrm{k}}+\left(\right.$ age $\left.* \beta_{1 k}\right)+\left(\right.$ age $\left.^{2} * \beta_{2}\right)=\hat{\pi}_{0}+v_{0 \mathrm{k}}+$ $\left(\right.$ age $\left.* \pi_{1}\right)+\left(\right.$ age $\left.* v_{1 \mathrm{k}}\right)+\left(\right.$ age $\left.^{2} * \beta_{2}\right)$, where $\beta_{1 \mathrm{k}}$ and $\beta_{2}$ are the effects of age and its square respectively, $\pi_{1}$ is the estimated fixed age effect coefficient, and $v_{1 \mathrm{k}}$ is the year random effects on the age coefficient in period k. Similar calculations yield results for 30 , 40, 50, and 60-year-old individuals.

The figures for both indicators show that 20-year-old people have experienced a more salient decrease since 2012. These findings support our fourth hypothesis that the decline in the political satisfaction level of young people in recent years has been greater than that of older people. In the aspect of satisfaction with the government, 20 and 60-year-old people had been the most satisfied since 1997. After 2012, 20-year-old people began to be less satisfied than 60-year-old people, but were still more satisfied than 30, 40, and 50-year-old people. In the aspect of the rating of the Chief Executive, from 2005 to 2012, 20-year-old people generally gave a higher rating than other age groups, but their rating became the lowest in 2014. The decline in their rating of the Chief Executive was more marked than that for satisfaction with the government.

Figure $2 \mathrm{c}$ presents the estimated overall period effects by birth cohort at the mean of age and control variables. The predicted level of satisfaction with the government and the rating of the Chief Executive for each year is calculated as $\hat{\pi}_{0}+v_{0 \mathrm{k}}+u_{0 \mathrm{jk}}$, where $u_{0 \mathrm{jk}}$ is the cohortspecific random effects coefficient of birth cohort $\mathrm{j}$ in period $\mathrm{k}$. It shows that there was no clear difference in trend in the level of satisfaction with the government and the rating of the Chief Executive among birth cohorts from 2004 to 2012. Since 2012, the level of satisfaction with the government and the rating of the Chief Executive of the cohort born in 1986 or later had dropped considerably more than those of other birth cohorts. They had become the most dissatisfied cohort and gave the most negative rating to the Chief Executive. This indicates that the decline in the latest cohort's level of political satisfaction in recent years is greater than that of earlier cohorts, supporting our fifth hypothesis. 
Our findings demonstrate that both the age and cohort effects interact with the period effects. The recent decline in the political satisfaction of the 20-year-old people and the latest cohort, who were born in 1986 or later, is more marked than that observed for older people and earlier birth cohorts. As mentioned before, we hypothesize that Leung's poor performance and the rise in the price of housing are possible reasons for these variations in the decline in political satisfaction. In the following sections, we examine our relevant hypotheses.

\subsection{Age and Cohort Variations in the Rule of the Chief Executive Effect}

Model 3, which includes two dummy variables of the ruling period of the Chief Executive, estimates the main effect of the rule of the Chief Executive. Leung's period of rule is selected as a reference because we plan to examine whether under his rule people are more dissatisfied than they were under the rules of the other two Chief Executives. Hence, the rules of Tung and Tsang are added in the regression analysis. As expected, the dummies for the rule of the Chief Executive are positive and statistically significant, while age, gender, education, cohort, and period effects are considered. Table 1 shows that the dummy coefficient for the rule of Tsang is .262, which exceeds the .001 level of significance, implying that under Tsang's rule people expressed a higher level of satisfaction with the government's performance than they did under the rule of Leung. But the dummy for the rule of Tung fails to exceed the level of significance. In Table 2, the coefficients for the dummies for the rule of Tung and Tsang are positive at the .001 level of significance. The former is 7.554 and the latter is 12.348 . This indicates that people are giving a poorer evaluation to Leung than to Tung and Tsang. The rating of Tsang is more positive than that of Tung.

Models 4 and 5 are additive models to Model 3. They include interaction terms for age with two dummy variables for the rule of the Chief Executive and random cohort variations for the coefficients for the dummies for the rule of the Chief Executive, respectively. In Model 4, two interaction terms are statistically significant in Tables 1 and 2. Their coefficients are negative at the .001 level of significance. Given that the coefficients for the dummies for the rule of Tung and Tsang remain positive, these findings indicate that the effects of the rule of the Chief Executive are weaker for older people. In other words, Leung's rule has a stronger negative impact on the political satisfaction of younger people than on that of older people. It supports our sixth hypothesis.

Figure 3 shows predicted variations in the effects of the rule of the Chief Executive on political satisfaction in terms of the estimated level of satisfaction with the government and the rating of the Chief Executive by age groups at the mean of the control variables and averaged over all cohorts and periods. The variation across the three Chief Executives is found to be larger for 20-year-olds than for other age groups, especially the older ones. Their estimated values for satisfaction with the government and the rating of the Chief Executive are 1.660 and 41.805 under Leung's rule, lower than those under Tung's rule by .067 and 10.106 points, as well as those under Tsang's rule by .373 and 17.696 points. These decreases are greater than those for older age groups. For example, for 60 -year-old people the estimated value of satisfaction with the government under Leung's rule is lower than that under Tsang's rule by .173 points, and their rating of the Chief Executive under Leung's rule is lower than that under the rules of Tung and Tsang by 6.986 and 9.136 points, respectively. Moreover, 60-year-old people were more satisfied with the government under the rule of Leung than of Tung. It is important to note that 20 -year-old people were the most satisfied age group under the rule of Tsang, but they became one of the least satisfied groups under that of Leung. This is consistent with previous findings that the drop 

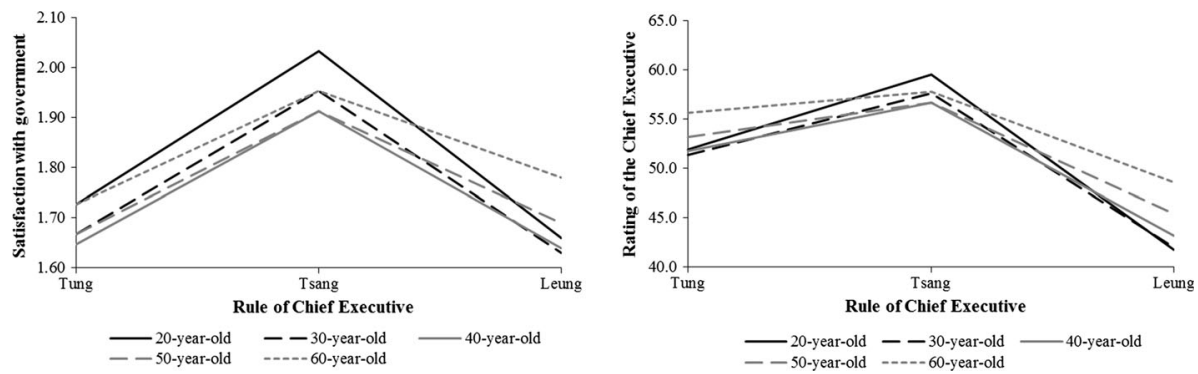

Fig. 3 Predicted variations in the effect of the rule of the Chief Executive on political satisfaction by age. Note The effects in terms of the predicted value of political satisfaction are estimated from Model 4

in the level of political satisfaction of 20-year-old people has been more pronounced since Leung was elected as Chief Executive in 2012.

Model 5 shows that there is no significant variation in the effect of the rule of the Chief Executive on both satisfaction with the government and the rating of the Chief Executive across birth cohorts. The cohort variance components for two dummies for the rule of the Chief Executive in Tables 1 and 2 are statistically insignificant. The impact of Leung's rule on political satisfaction is constant across successive birth cohorts. Our seventh hypothesis is disproved.

\subsection{Age and Cohort Variations in the Effect of Housing Prices}

In order to examine the overall effect of housing prices on political satisfaction, in Model 6 we added the CCI to the regression analysis. The coefficient of the CCI in Table 2 is negative at the .001 level of significance, but fails to exceed significance in Table 1. This shows that housing prices are negatively correlated with the rating of the Chief Executive. People gave the Chief Executive a poorer evaluation when housing prices rose. However, the public's satisfaction with the government remained constant regardless of whether housing price rose or not.

Similar to the rule of the Chief Executive, we test variations in the effect of housing prices among age and birth cohorts by including the interaction terms for age with the CCI and random cohort variations in the CCI's coefficient in Models 7 and 8, respectively. In Model 7, the interaction terms between age and the CCI in Tables 1 and 2 are positive at the .001 level of significance. The coefficient of the CCI is negative and statistically significant in Table 2, but is insignificant in Table 1. Figure 4a shows predicted variations in the effect of the CCI on political satisfaction in terms of the estimated level of satisfaction with the government and the rating of the Chief Executive by age groups at the mean of the control variables and averaged over all cohorts and periods estimated from Model 7. It demonstrates that young people are more dissatisfied than people of other age groups when housing prices rise. For 20 and 30-year-old people, there is a negative relationship between the CCI and satisfaction with the government and the rating of the Chief Executive. Although the rating of the Chief Executive given by other age groups correlates negatively with the CCI, the trends are flatter than those of the 20 and 30-year-olds. Moreover, as the CCI increases, the other age groups are more satisfied with the government's performance. Therefore, the suggestion that rising housing prices will have a negative impact on political satisfaction is valid for young people only, supporting our eighth hypothesis.

Model 8 indicates that there is significant variation in the effect of housing prices across birth cohorts. The cohort variance components for the CCI in Tables 1 and 2 are 

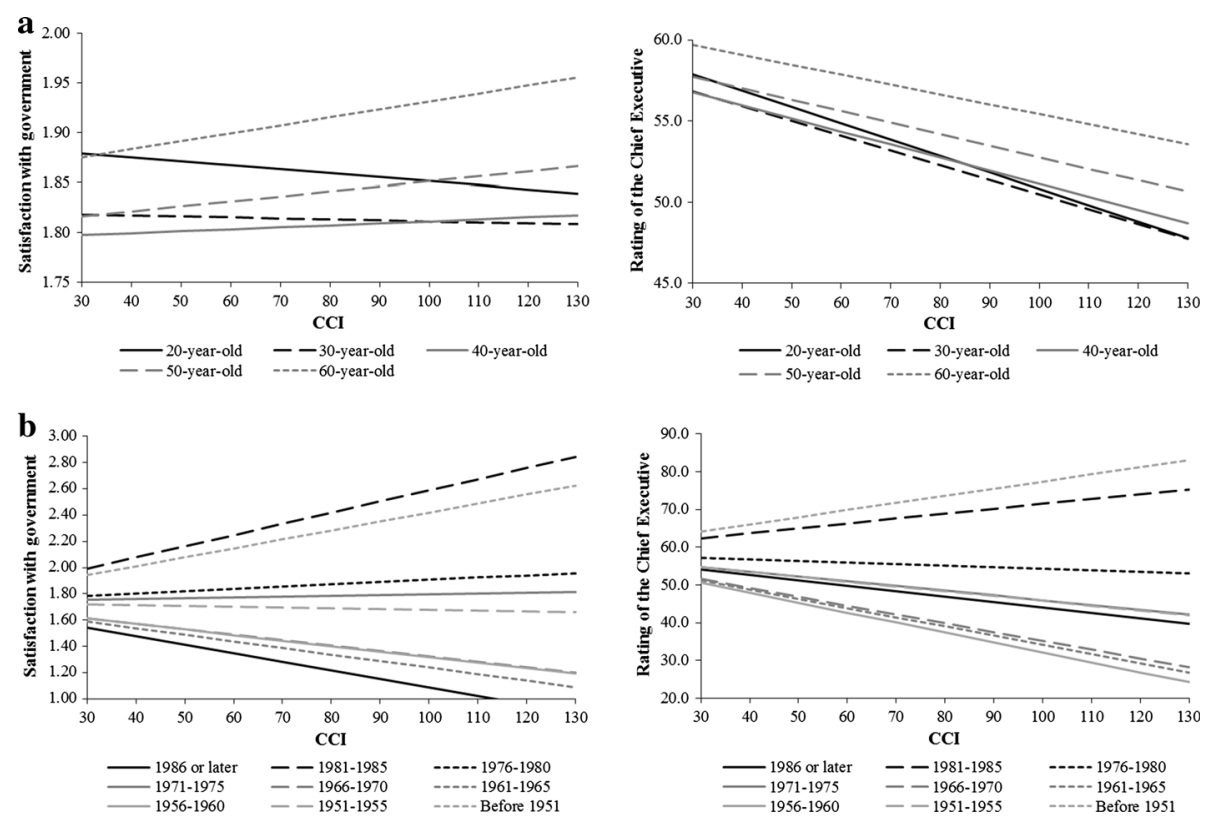

Fig. 4 Predicted variations in the effect of housing prices on political satisfaction by age and cohort, a Model 7: effect of housing prices by age, b Model 8: effect of housing prices by cohort. Note The effects in terms of the predicted value of political satisfaction are estimated from Models 7 and 8

statistically significant. Figure $4 \mathrm{~b}$ displays the estimated effects of the $\mathrm{CCI}$ by birth cohorts in terms of the predicted level of satisfaction with the government and the rating of the Chief Executive for each cohort at the mean of age and control variables and averaged over all periods estimated from Model 8, which is calculated as $\hat{\pi}_{0}+u_{0 \mathrm{j}}+\left(\mathrm{CCI} * \beta_{3 \mathrm{j}}\right)=$ $\hat{\pi}_{0}+u_{0 \mathrm{j}}+\left(\mathrm{CCI} * \pi_{3}\right)+\left(\mathrm{CCI} * u_{3 \mathrm{j}}\right)$, where $\beta_{3 \mathrm{j}}$ are the effects of CCI, $\pi_{3}$ is the estimated fixed effect coefficient of CCI, and $u_{3 \mathrm{j}}$ is cohort random effects on the CCI coefficient. The results show that there is no consistent direction in the relationship between political satisfaction and housing prices across birth cohorts. The correlation between political satisfaction and housing prices is negative for the cohorts born between 1956 and 1960, 1961 and 1965, 1966 and 1970, as well as those born in 1986 or later, but is positive for those born before 1951 and between 1981 and 1985. The CCI trend is comparatively flat for the other cohorts. In other words, cohort gap in political satisfaction varies with housing prices. Differences between the cohorts will grow when housing prices increase.

The findings partially support our last hypothesis. For the latest cohort, who were born in 1986 or later, the impact of rising housing prices on political satisfaction is more negative than it is for particular earlier cohorts including those born before 1951, between 1971 and 1975, 1976 and 1980, as well as 1981 and 1985, because these earlier cohorts' level of satisfaction with the government and the rating of the Chief Executive are either stable or have risen along with the rise in housing prices. However, similar to the cohort born in 1986 or later, some earlier cohorts who were born between 1956 and 1960, 1961 and 1965, and 1966 and 1970 have become more dissatisfied since housing prices have risen. Compared to the cohort born in 1986 or later, rising housing prices have had a less negative impact on their level of satisfaction with the government, but not on their rating of 
the Chief Executive. Hence, we cannot prove that the impact of rising housing prices on the political satisfaction of the latest cohort is more negative than it is for all earlier cohorts.

It is interesting to note that the direction of the relationship between political satisfaction and housing prices differs between the latest two cohorts. The second-latest cohort, who were born between 1981 and 1985, became more politically satisfied as housing prices increased, but the latest cohort, who were born in 1986 or later, became more dissatisfied. The later cohorts enjoy living their own lives, so after they have worked for some years they prefer to move out of the family home and live alone. The rise in housing prices forces them to continue to live with their parents. This is one reason why the cohort born in 1986 or later is dissatisfied with the government's failure to prevent the continued rise of housing prices. Although the cohort born between 1981 and 1985 also enjoy an individual lifestyle, in childhood or early adulthood they experienced social problems resulting from falling housing prices brought about by the outbreak of the Asian Financial Crisis in 1997. The rapid decline in housing prices caused large numbers of people to fall into negative equity. The problem of negative equity was not alleviated until Hong Kong's economy began to recover after 2003. To this cohort, housing prices are an indicator of economic development. The rise in the price of housing is an indication of economic growth, and vice versa. By contrast, the cohort born in 1986 or later was too young during this period to really experience negative equity as social problem.

\subsection{Other Findings}

Males and people with a tertiary education were found to be less politically satisfied than females and people without a tertiary education, controlling for age, cohort, period, the ruling Chief Executive, and housing prices. In Tables 1 and 2, the coefficients for female and tertiary educated exceed the .001 level of significance across all models. The former is positive while the latter is negative. Because the new generation is better educated than the older ones, education can account for their low level of political satisfaction. Rising levels of education lead to an increase in political dissatisfaction.

\section{Discussion}

In most previous studies on young people in Hong Kong, no simultaneous assessment was made of the effects of age, period, and cohort on political satisfaction. These studies suffer from the problem of identification induced by an exact linear dependency between age and cohort. There were no assessments of the net effect of age and cohort and of the possibility of heterogeneity in the period effect over the course of life and across successive birth cohorts. Using a pooled dataset of repeated cross-sectional surveys from 1997 to 2014 and an improved APC analysis-CCREM, our study is a more comprehensive examination of the net effects of age and cohort on political satisfaction in Hong Kong and possible heterogeneity in the period effect among various age groups and birth cohorts.

The major findings of our study are as follows. First, there is a U-shaped relationship between age and political satisfaction, independent of birth cohort and period effects. Middle-aged people were found to be the most dissatisfied group, while the elderly were the most satisfied. Young people had a lower level of satisfaction than the elderly, although their satisfaction and rating were higher than those of middle-aged people. Second, compared with age effects, cohort effects are weak and have limited power to explain 
political satisfaction. Third, both age and cohort effects were found to interact with period effects. The recent decline in the political satisfaction of 20-year-olds and of the cohort born in 1986 or later is more marked than that of older people and earlier birth cohorts. Fourth, the effects of age differed across the terms of the three Chief Executives. Young people were found to be much more dissatisfied under Leung's rule than older people. Last, the effect of housing prices on political satisfaction was found to vary among age and birth cohorts. Some age groups and birth cohorts would be more politically satisfied as the price of housing increases, while other groups would not. In other words, the rise in housing prices widens the gap in political satisfaction among different age groups and birth cohorts.

These findings help to clear the puzzle of the rise of youth activism in recent Hong Kong social movements. Cohort effects do not indicate a linear decrease in the level of satisfaction across successive cohorts, which does not largely support the post-materialist argument that a rise in the quality of the living environment in childhood has caused the later Hong Kong cohorts to incline towards post-materialistic values, to become less satisfied with the government and other hierarchical institutions, and thus to be more active in local politics than earlier cohorts. Differences between the latest cohort and earlier cohorts in childhood and early adulthood experiences are insufficient to explain why young people in Hong Kong are more dissatisfied than elderly people. On the other hand, Hong Kong people were found to be more politically dissatisfied at a young age than in old age. In addition, being tertiary educated was found to be negatively correlated with indicators of political satisfaction, and the new generation has had more chances than the older generations to receive a tertiary education. Hence, the new generation is more dissatisfied because of their age and high level of education, rather than because of their cohort.

However, age effects should not be the sole factor in the rise of the youth movement in Hong Kong because young people are not the most dissatisfied group. Our results show that there have been some social or political developments in recent years that have led to a more significant decline in the level of political satisfaction of young people. The pronounced increase in the political discontent of these groups is believed to have been behind the outbreak of the large-scale youth social movement in 2014 in Hong Kong. One possible periodic factor interacting with the age effects is the performance of the present Chief Executive Leung. The drop in the level of political satisfaction under Leung's rule was found to be more pronounced among 20-year-olds than among older people. Why do young people dislike Leung's rule so much more than older people? The soaring housing prices in recent years are one explanation. Our findings confirm the validity of the argument that for young people of about the age of 20 , but not for all age groups, rising housing prices had a negative impact on their satisfaction with the government and their rating of the Chief Executive. As mentioned before, Hong Kong young people would like to leave their family and live alone, so they expect the government to prevent the price of housing from soaring or even to cause prices to fall. But Leung has failed to do this, causing great disappointment among young people. Comparatively, the negative impacts of increasing housing prices on the political satisfaction of the middle-aged are limited. This is one reason why middle-aged people have been more silent in recent social movements. Leung's ruling style and lack of capacity to effect changes in other policy areas such as cross-border issues may also have a stronger negative impact on the political satisfaction of young people. Unfortunately, due to limited data, we cannot conduct an empirical analysis on the interaction of these factors with age. A further study employing APC analysis is needed to determine which aspects of Leung's rule are enhancing the political dissatisfaction of youth.

Finally, the paper supports Braungart and Braungart's (1986) argument that the emergence of a youth movement is the result of an interaction between life course development, 
cohort experiences, and social trends, rather than the result of either life-course forces or cohort experiences. It was found in Hong Kong that rising housing prices had a stronger negative impact on satisfaction with the government and the rating of the Chief Executive for young people of about the age of 20 and for the latest cohort born in 1986 or later than for the others. It is suggested that future research on the rise of the youth movement in Hong Kong and other places should consider the possible interaction effects of age and cohort with period-level variables while conducting an APC analysis.

Acknowledgments This research was supported by the Public Policy Research Funding Scheme of the Central Policy Unit, the Government of the Hong Kong Special Administrative Region (Project Number: 2015.A4.011.15C). We are grateful to the two anonymous reviewers for their comments.

\section{Appendix}

See Table 3.

Table 3 Descriptive statistics of the variables in the analysis

\begin{tabular}{|c|c|c|c|c|}
\hline Variable & Mean & SD & Max. & Min. \\
\hline Satisfaction with the government & 1.87 & .74 & 3 & 1 \\
\hline Rating of the Chief Executive & 53.17 & 20.13 & 100 & 0 \\
\hline Age & 42.64 & 14.90 & 97 & 18 \\
\hline \multirow[t]{2}{*}{$\mathrm{CCI}$} & 68.28 & 27.40 & 130.16 & 31.34 \\
\hline & & & & $\%$ \\
\hline Female & & & & 51.7 \\
\hline Tertiary educated & & & & 31.0 \\
\hline \multicolumn{5}{|l|}{ Cohort } \\
\hline Before 1951 & & & & 18.3 \\
\hline $1951-1955$ & & & & 10.1 \\
\hline $1956-1960$ & & & & 12.7 \\
\hline $1961-1965$ & & & & 14.6 \\
\hline $1966-1970$ & & & & 11.7 \\
\hline $1971-1975$ & & & & 10.2 \\
\hline 1976-1980 & & & & 8.6 \\
\hline 1981-1985 & & & & 7.4 \\
\hline 1986 or later & & & & 6.5 \\
\hline \multicolumn{5}{|l|}{ Rule of the Chief Executive } \\
\hline Tung & & & & 40.7 \\
\hline Tsang & & & & 44.4 \\
\hline \multirow[t]{2}{*}{ Leung } & & & & 14.9 \\
\hline & & Start & & End \\
\hline Period & & $1997 / 07$ & & $2014 / 12$ \\
\hline
\end{tabular}

Observation $=155,278$ 


\section{References}

Blanchflower, D. G., \& Oswald, A. J. (2004). Well-being over time in Britain and the USA. Journal of Public Economics, 88(7-8), 1359-1386.

Blanchflower, D. G., \& Oswald, A. J. (2008). Is well-being U-shaped over the life cycle? Social Science and Medicine, 66(8), 1733-1749.

Braungart, R. G., \& Braungart, M. M. (1986). Life-course and generational politics. Annual Review of Sociology, 12, 205-231.

Brockmann, H. (2010). Why are middle-aged people so depressed? Evidence from West Germany. Social Indicators Research, 97(1), 23-42.

Centadata. (2015). Centa-city index. http://hk.centadata.com/cci/cci_e.htm. Accessed 1 June 2015.

Cheng, J. Y. S. (2014). The emergence of radical politics in Hong Kong: Causes and impact. The China Review, 14(1), 199-232.

Clark, A. E. (2007). Born to be mild? Cohort effects don't (fully) explain why well-being is U-shaped in age. IZA Discussion Paper No. 3170.

Easterlin, R. A. (2006). Life cycle happiness and its sources: Intersections of psychology, economics, and demography. Journal of Economic Psychology, 27(4), 463-482.

Elder, G. H, Jr. (1974). Children of the great depression: Social change in life experience. Chicago: University of Chicago Press.

Glenn, N. D. (2003). Distinguishing age, period, and cohort effects. In J. T. Mortimer \& M. J. Shanahan (Eds.), Handbook of the life course (pp. 465-476). New York: Kluwer Academic/Plenum Publishers.

Gove, W. R., Ortega, S. T., \& Style, C. B. (1989). The maturational and role perspectives on aging and self through the adult years: An empirical evaluation. American Journal of Sociology, 94(5), 1117-1145.

Hong Kong Institute of Asia-Pacific Studies. (2015). Survey findings on the HKSAR government's popularity in December 2014 and the expectations on the 2015 Policy Address. Hong Kong: Hong Kong Institute of Asia-Pacific Studies, The Chinese University of Hong Kong.

Inglehart, R. (1977). The silent revolution: Changing values and political styles among Western publics. Princeton: Princeton University Press.

Inglehart, R. (1999). Postmodernization erodes respect for authority, but increases support for democracy. In P. Norris (Ed.), Critical citizens: Global support for democratic government (pp. 236-256). Oxford: Oxford University Press.

Jewell, S., \& Kambhampati, U. S. (2015). Are happy youth also satisfied adults? An analysis of the impact of childhood factors on adult life satisfaction. Social Indicators Research, 121(2), 543-567.

Kotzian, P. (2010). Public support for liberal democracy. International Political Science Review, 32(1), $23-41$.

Li, N. (2015). Multidimensionality of longitudinal data: Unlocking the age-happiness puzzle. Social Indicators Research,. doi:10.1007/s11205-015-1032-4.

Lipset, S. M., \& Schneider, W. (1983). The decline of confidence in American institutions. Political Science Quarterly, 98(3), 379-402.

Lu, P. (2014). A comparative analysis of political confidence in the BRICS countries. Japanese Journal of Political Science, 15(3), 417-441.

Ma, N. (2015). The rise of "anti-China" sentiments in Hong Kong and the 2012 Legislative Council elections. The China Review, 15(1), 39-66.

Mannheim, K. (1952). The problem of generations. In P. Kecskemeti (Ed.), Essays on the sociology of knowledge (pp. 276-322). London: Routledge \& Kegan Paul.

Quaranta, M. (2015). An apathetic generation? Cohorts' patterns of political participation in Italy. Social Indicators Research,. doi:10.1007/s11205-015-0869-x.

Robinson, R. V., \& Jackson, E. F. (2001). Is trust in others declining in America? An age-period-cohort analysis. Social Science Research, 30(1), 117-145.

Ryder, N. B. (1965). The cohort as a concept in the study of social change. American Sociological Review, 30(6), 843-861.

Tang, Z. (2014). They are richer but are they happier? Subjective well-being of Chinese citizens across the reform era. Social Indicators Research, 117(1), 145-164.

Wang, Z. (2010). Citizens' satisfaction with government performance in six Asian-Pacific giants. Japanese Journal of Political Science, 11(1), 51-75.

Wong, T. K. Y., Hsiao, H. H. M., \& Wan, P. S. (2009). Comparing political trust in Hong Kong and Taiwan: Levels, determinants, and implications. Japanese Journal of Political Science, 10(2), 147-174.

Yang, Y. (2008). Social inequalities in happiness in the United States, 1972 to 2004: An age-period-cohort analysis. American Sociological Review, 73, 204-226. 
Yang, Y., \& Land, K. C. (2006). A mixed models approach to the age-period-cohort analysis of repeated cross-section surveys, with an application to data on trends in verbal test scores. Sociological Methodology, 36, 75-97.

Yang, Y., \& Land, K. C. (2008). Age-period-cohort analysis of repeated cross-section surveys: Fixed or random effects? Sociological Methods and Research, 36(3), 297-326.

Yang, Y., \& Land, K. C. (2013). Age-period-cohort analysis: New models, methods, and empirical applications. Boca Raton: CRC Press. 